VNU Journal of Science: Legal Studies Journal homepage: https://js.vnu.edu.vn/LS

\title{
Review Article \\ Weaknesses of the Law Formulation in Vietnam and Solutions
}

\author{
Hoang Thi Kim Que*, Le Thi Phuong Nga \\ VNU School of Law, 144 Xuan Thuy, Cau Giay, Hanoi, Vietnam
}

Received 13 August 2020

Revised 11 September 2020; Accepted 18 December 2020

\begin{abstract}
Law-making activities have gained many important achievements, since the 2013 Constitution was enacted, formulating the legal basis for the protection and assurance of the rights and interests of the people as well as nationwide socio-economic development. However, there are still many shortcomings and weaknesses in the formulation of the law such as instability lead to the high frequency of amendments and supplements; overlap, inconsistencies between legal regulations, and inconsistent with social life; sanctions are not appropriate, etc,... Therefore, we need urgent solutions to overcome the mentioned shortcomings to ensure the quality and effectiveness of law-making to meet practical requirements.
\end{abstract}

Keywords: Making law, stability, overlap, feasibility, solutions, legal control, quality of legal documents.

\footnotetext{
${ }^{*}$ Corresponding author.

E-mail address: quekim016@yahoo.com
}

https://doi.org/10.25073/2588-1167/vnuls.4317 


\title{
Một số hạn chế chủ yếu và giải pháp khắc phục trong xây dựng pháp luật ở nước ta hiện nay
}

\author{
Hoàng Thị Kim Quế*, Lê Thị Phương Nga \\ Khoa Luật, Đại học Quốc gia Hà Nội, 144 Xuân Thủy, Cầu Gián, Hà Nội, Việt Nam \\ Nhận ngày 13 tháng 8 năm 2020 \\ Chỉnh sửa ngày 11 tháng 9 năm 2020; Chấp nhận đăng ngày 18 tháng 12 năm 2020
}

\begin{abstract}
Tóm tắt: Hoạt động xây dựng pháp luật kể từ khi Hiến pháp năm 2013 đến nay đã đạt được nhiều thành tựu quan trọng, đặt cơ sở pháp lý cho việc bảo vệ, bảo đảm quyền, lợi ích của người dân và phát triển kinh tế, xã hội của đất nước. Tuy vậy, trong xây dựng pháp luật vẫn còn nhiều hạn chế, nhược điểm cơ bản như: tính ổn định thấp, tần suất sửa đổi, bổ sung cao, sự chồng chéo, mâu thuẫn giữa các quy định pháp luật, chưa phù hợp thực tiễn; chế tài xử lý vi phạm chưa phù hợp,... Do đó, cần thực hiện các giải pháp cấp bách để khắc phục những khuyết điểm nêu trên nhằm đảm bảo chất lượng, hiệu quả xây dựng pháp luật đáp ứng yêu cầu thực tiễn.

Tù khóa: Xây dựng pháp luật, tính ổn định, chồng chéo, tính khả thi, giải pháp, kiểm soát pháp luật, chất lượng văn bản pháp luật.
\end{abstract}

\section{Dẫn nhập}

Xây dựng pháp luật là lĩnh vực rộng lớn, được tiếp cận, đánh giá từ nhiều phương diện. Cùng với những thành tựu to lớn trong công cuộc xây dựng, phát triển đất nước, hệ thống pháp luật nước ta ngày càng được hoàn thiện cả về nội dung và quy trình, thủ tục. Đặc biệt là từ năm 2013 đến nay, nhiều bộ luật cơ bản cùng các văn bản quy phạm pháp luật quan trọng khác đã thể chế hóa các nguyên tắc pháp quyền, dân chủ cơ bản của Hiến pháp năm 2013. Hệ thống pháp luật đã từng bước được hoàn thiện ở hầu hết lĩnh vực của đời sống xã hội, tạo cơ sở pháp lý cho các hoạt động kinh tế, văn hóa, xã hội, bảo vệ các quyền, lợi ích của người dân, doanh nghiệp, nâng cao hiệu lực, hiệu quả quản lý của nhà nước.

Tuy vậy, trong xây dựng pháp luật nói riêng và hệ thống pháp luật nói chung còn nhiều hạn chế, nhược điểm, có tác động tiêu cực đến thực hiện pháp luật của các cá nhân, tổ chức và hoạt động quản lý, thi hành pháp luật của các cơ

\footnotetext{
* Tác giả liên hệ.

Địa chỉ email: quekim016@yahoo.com

https://doi.org/10.25073/2588-1167/vnuls.4317
}

quan nhà nước. Đây là vấn đề rộng lớn, trong phạm vi bài viết này chúng tôi xin được đề cập đến những hạn chế chủ yếu và một số giải pháp khắc phục nhằm đảm bảo chất lượng các văn bản pháp luật, đáp ứng yêu cầu của thực tiễn cuộc sống.

\section{Một số hạn chế chủ yếu trong hệ thống pháp luật từ phương diện xây dựng pháp luật}

2.1. Tình trạng chồng chéo, mâu thuẫn, xung đột giữa các văn bản quy phạm pháp luật

Một trong những hạn chế, bất cập lớn trong hoạt động xây dựng pháp luật là tình trạng chồng chéo, mâu thuẫn, xung đột giữa các văn bản luật và các văn bản dưới luật. Thực trạng này dẫn đến nhiều khó khăn cho việc thực hiện pháp luật của người dân, doanh nghiệp và thi hành pháp luật của các cơ quan nhà nước. Trên bình diện chung, còn tồn tại sự chồng chéo, xung đột giữa các đạo luật với nhau, giữa luật chung và luật chuyên ngành, giữa văn bản hướng dẫn luật này và văn bản hướng dẫn luật khác, dẫn đến tình trạng "làm theo luật này thì đúng, luật khác thì sai”. Tình trạng còn nhiều 
văn bản pháp luật chồng chéo, mâu thuẫn lẫn nhau, thậm chí triệt tiêu lẫn nhau, tình trạng "pháp luật triệt tiêu pháp luật" là hiện tượng không bình thường. Nhưng hiện tượng đó vẫn diễn ra, thậm chí còn khá phổ biến hiện nay,... [1].

Điển hình nhất là sự chồng chéo, mâu thuẫn, xung đột giữa các văn bản quy phạm pháp luật trong các lĩnh vực: đất đai, đầu tư, xây dựng, quy hoạch; nhà ở, kinh doanh bất động sản, môi trường, vệ sinh, an toàn thực phẩm,... Trong báo cáo của Phòng Thương mại và Công nghiệp Việt Nam (VCCI) về thu thập, hệ thống lại, làm rõ những điểm chồng chéo, xung đột giữa các quy định theo chỉ đạo của Thủ tướng Chính phủ đã nêu lên 20 điểm xung đột, chồng chéo lớn của pháp luật về đầu tư, đất đai, xây dựng, môi trường, đấu thầu, tiêu biểu như giữa các văn bản luật: Luật xây dựng, Luật đầu tư, Luật đất đai, Luật kinh doanh bất động sản, Luật quy hoạch đô thị, Luật đấu thầu; Luật Nhà ở, v.v... [2].

Sự chồng chéo, mâu thuẫn giữa các quy định pháp luật cũng tồn tại trong hoạt động thanh tra, kiểm toán đối với doanh nghiệp nhà nước. Nhiều trường hợp doanh nghiệp không biết phải thực hiện theo quy định nào, thực hiện quy định này thì lại vi phạm quy định kia [3]. Trong lĩnh vực tài nguyên khoáng sản cũng tồn tại nhiều bất cập như hiện tượng cấp phép tràn lan, quản lý chồng chéo. Theo chuyên gia kinh tế Lê Đăng Doanh, ở đây có vấn đề lợi ích nhóm trong khai thác khoáng sản, khai thác khoáng sản vừa làm cho người dân phải chịu ô nhiễm môi trường, đói nghèo, trong khi tài nguyên bị lấy đi thì khai thác để làm gì, cho ai [4]. Sự cồng kềnh, bất cập và mâu thuẫn, chồng chéo làm giảm tính minh bạch của pháp luật, khiến cho pháp luật trở nên phức tạp, khó hiểu và khó áp dụng, hiệu lực và hiệu quả điều chỉnh thấp. Sự xung đột, chồng chéo giữa các văn bản pháp luật gây ra nhiều tác động tiêu cực đối với các đối tượng phải tuân thủ pháp luật như sự lãng phí thời gian, công sức, tiền bạc, lỡ cơ hội đầu tư, làm tăng chi phí và rủi ro đối với hoạt động kinh doanh. Đồng thời, các xung đột, chồng chéo này cũng là những cản trở đối với việc thực hiện pháp luật, làm giảm niềm tin vào pháp luật, tạo cơ hội phát sinh các hiện tượng nhũng nhiễu, tiêu cực, tham nhũng nhất là trong thực hiện các công trình, chương trình phát triển kinh tế, văn hóa, xã hội.

Có nhiều nguyên nhân khách quan và chủ quan về thực trạng chồng chéo, mâu thuẫn, xung đột giữa các văn bản pháp luật. Một cách tổng quan nhất, có thể nêu một số nguyên nhân chủ yêu sau đây.

Thứ nhất, đó là sự bất cập, hạn chế ngay chính trong cơ chế phân công, phối hợp, kiểm soát giữa các cơ quan nhà nước trong xây dựng, thực thi chính sách, pháp luật. Cho đến hiện nay, mặc dù chúng ta đã đạt nhiều kết quả quan trọng về cải cách bộ máy nhà nước, về phân công chức năng, nhiệm vụ của các cơ quan trong bộ máy nhà nước song vẫn còn có sự chồng chéo, bất hợp lý về chức năng, nhiệm vụ, thẩm quyền quản lý của các cơ quan nhà nước từ trung ương đến địa phương. Chẳng hạn như chưa có sự thống nhất, đồng bộ giữa Luật Đầu tư và các Luật khác có liên quan, sự chồng chéo, trùng lặp về nội dung quản lý, về cơ quan thẩm định, phê duyệt, xung đột giữa Luật Đầu tư và Luật dầu khí trong triển khai các dự án dầu khí. Hoặc còn có những bất cập, thậm chí chưa phân định rõ ràng ranh giới về thẩm quyền giữa các cơ quan trong lĩnh vực hoạt động thanh tra và kiểm toán, đặc biệt là giữa kiểm toán với thanh tra chuyên ngành.

Trên thực tế, còn có sự cắt khúc trong xây dựng pháp luật: từ đề xuất xây dựng mới đến đề nghị sửa đổi, bổ sung các văn bản pháp luật. Do vậy, chính từ việc chưa xác định rõ ràng, dứt khoát về chức năng, nhiệm vụ của các cơ quan nhà nước đã dẫn đến sự chồng chéo, mâu thuẫn trong nội dung các văn bản quy phạm pháp luật của họ.

Thứ hai, chưa hoàn toàn bóc tách giữa công đoạn xây dựng và phân tích chính sách với công đoạn soạn thảo văn bản pháp luật. Xây dựng chính sách, pháp luật của chúng ta vẫn còn thiếu tính chuyên nghiệp, năng lực, trình độ chuyên môn nghiệp vụ về xây dựng chính sách và soạn thảo văn bản pháp luật của đội ngũ cán bộ, công chức còn yếu kém.

Thứ ba, về phương diện trách nhiệm: trách nhiệm của cơ quan soạn thảo, của người đứng đầu, của các bộ phận tham mưu, trách nhiệm 
giải trình, tuy đã được quy định nhưng còn chung chung, đặc biệt là còn thiếu các chế tài xử lý vi phạm trong xây dựng pháp luật, chế tài đối với việc ban hành các văn bản pháp luật sai trái.

Thứ tư, hạn chế trong việc chủ động phối hợp, chia sẻ thông tin giữa các cơ quan nhà nước trong xây dựng chính sách, pháp luật.

Thứ năm, ở mức độ nhất định, vẫn còn biểu hiện cài cắm lợi ích nhóm vào trong xây dựng, trong nội dung các văn bản pháp luật, kể cả tư duy bao cấp, tư duy né tránh trách nhiệm,... vẫn còn ít nhiều hiện hữu. Đây là những hạn chế mà thời gian gần đây đã được các đại biểu Quốc hội, lãnh đạo Chính phủ và các doanh nghiệp đề cập.

\subsection{Tính ổn định của pháp luật thấp, thường xuyên phải sửa đổi, bổ sung}

Một trong những hạn chế lớn trong xây dựng pháp luật là chưa đảm bảo tính thống nhất, đồng bộ và thiếu tính ổn định của hệ thống pháp luật. Tần suất sửa đổi, bổ sung, hủy bỏ văn bản pháp luật còn rất cao. Nhiều văn bản pháp luật tuổi thọ rất ngắn, thậm chí mới ban hành đã phải tạm hoãn thực hiện hoặc phải sửa đổi, bổ sung. Hạn chế này cũng đã được Thủ tướng Chính phủ Nguyễn Xuân Phúc đề cập trong Hội nghị toàn quốc triển khai công tác tư pháp năm 2017, pháp luật nước ta: "chất lượng còn thấp, thiếu ổn định nên thường xuyên phải sửa đổi, bổ sung" [5].

Pháp luật luôn phải thích ứng với sự thay đổi liên tục của thực tiễn cuộc sống. Việc sửa đổi, bổ sung các văn bản pháp luật về nguyên tắc là điều cần thiết. Tuy nhiên, nếu pháp luật thường xuyên thay đổi sẽ dẫn đến những tác động tiêu cực tới quyền, lợi ích của các cá nhân, tổ chức. Pháp luật thường xuyên bị thay đổi, gây nên nhiều khó khăn trong thực hiện pháp luật, đồng thời cũng gây khó khăn cho chính hoạt động quản lý của bộ máy nhà nước. Ngạn ngữ Anh có câu: "Pháp luật thay đổi thường xuyên thì tệ hơn là không có pháp luật" (The law that changes every day is worse than no law at all).

Có nhiều nguyên nhân dẫn đến tính ổn định thấp của pháp luật, thường xuyên phải sửa đổi, bổ sung hay hủy bỏ. Trong đó có vấn đề về trình độ, năng lực xây dựng, phân tích chính sách, soạn thảo văn bản pháp luật, tầm nhìn chiến lược cho sự phát triển các lĩnh vực kinh tế - xã hội.

Xét từ phương diện hoạt động xây dựng pháp luật của các cơ quan nhà nước, một trong những nguyên nhân quan trọng của tình trạng pháp luật thiếu tính thống nhất và tính ổn định, thường xuyên thay đổi là "sự phối hợp yếu kém giữa các bộ, ngành đề xuất dự án Luật đều đưa ra vấn đề có lợi cho quản lý, điều hành chỉ đạo của bộ, ngành đó, nhưng thiếu cái nhìn tổng thể chung; thậm chí có dự án Luật đưa ra nhưng ngay trong Chính phủ chưa thống nhất, và "tâm lý phổ biến là cứ thấy vướng thì đòi sửa luật ngay, trong khi vướng mắc nhiều khi lại không nằm ở luật" [6].

2.3. Chưa thực hiên đúng các yêu cầu về xây dựng, phân tích chính sách trong quy trình xây dụing pháp luật

Để đảm bảo chất lượng của pháp luật, cần phải thực hiện tốt việc xây dựng, phân tích chính sách - cơ sở lý luận, thực tiễn quan trọng cho việc soạn thảo nội dung các văn bản pháp luật. Về cơ sở pháp lý, Luật ban hành văn bản quy phạm pháp luật năm 2015 đã đổi mới cơ bản quy trình xây dựng, ban hành văn bản theo hướng tách bạch quy trình xây dựng chính sách với quy trình soạn thảo luật, pháp lệnh, nghị định, quy định quy trình xây dựng chính sách cần được thông qua, phê duyệt trước khi bắt đầu soạn thảo văn bản. Nhưng trong thực tiễn, công đoạn xây dựng, phân tích, lấy ý kiến góp ý rộng rãi, đánh giá tác động chính sách, pháp luật còn nhiều hạn chế. Việc thực hiện công đoạn xây dựng, phân tích chính sách vẫn còn nhiều hạn chế cả về sự đầu tư và chất lượng.

Sự bất cập, sự đồng nhất hai quá trình: xây dựng, phân tích chính sách và soạn thảo văn bản pháp luật. Đây có thể coi là một trong những hạn chế lớn nhất của quy trình lập pháp hiện nay. Các đề nghị xây dựng luật nhiều khi mới chỉ là cảm tính, chura đưa được cuộc sống vào luật [7]. Nhiều dự án do vậy đã phải soạn thảo lại, sửa đổi nhiều lần, gây lãng phí lớn về thời gian, công sức và tiền bạc. Theo chuyên gia kinh tế Phạm Chi Lan, để có một chính phủ 
kiến tạo và phục vụ, mong muốn và quyết tâm của Thủ tướng là chưa đủ. Một chính phủ kiến tạo chỉ có được trên nền tảng một thể chế đủ mạnh, với những chuẩn mực minh bạch, có thể giám sát, đo lường và đánh giá được [8].

\subsection{Hạn chế về thực hiện đánh giá tác động của} chinh sách, pháp luật, lấy ý kiến, phản biện xã hội đối với dụ thảo văn bản quy phạm pháp luật

Trong thực tiễn xây dựng pháp luật, còn nhiều hạn chế trong việc đánh giá tác động của các chính sách, pháp luật theo quy định của Luật ban hành văn bản quy phạm pháp luật năm 2015. Thậm chí còn có ý kiến đề nghị bỏ quy định về đánh giá tác động của chính sách, vì khó quá, phức tạp quá. Mặc dù vậy, do tầm quan trọng của vấn đề, Thứ trưởng Bộ Tư pháp Phan Chí Hiếu đã khẳng định kiên quyết phải thực hiện yêu cầu này": Luật đã thay đổi thì chúng ta cũng phải thay đổi tư duy, phải coi khâu đề nghị chính sách, trong đó có đánh giá tác động của chính sách là quan trọng, thậm chí là quan trọng nhất trong quy trình xây dựng chính sách" [9].

Việc tổ chức lấy ý kiến, tham vấn của các chuyên gia, các tổ chức pháp lý, xã hội, người dân và doanh nghiệp còn nhiều hạn chế. Có nhiều dự thảo văn bản mới chỉ dừng lại ở việc lấy ý kiến của các cơ quan, tổ chức liên quan, hầu như chưa lấy ý kiến của đối tượng chịu sự tác động trực tiếp của văn bản. Do việc gửi dự thảo văn bản xin ý kiến thường là chậm nên không đảm bảo đủ thời gian cần thiết để cho các cá nhân, tổ chức liên quan nghiên cứu, đóng góp ý kiến, phản biện. Trên thực tế, ở nhiều nới tuy có tổ chức lấy ý kiến góp ý, tham vấn song nội dung, chất lượng của các ý kiến góp ý còn sơ sài, nặng về câu chữ, kỹ thuật trình bày văn bản mà chưa tập trung nhiều vào các nội dung của dự thảo văn bản.

2.5. Chất luợng của văn bản quy phạm pháp luật chưa đảm bảo, chua phù hợp thực tiê̂n, tính khả thi thấp, còn tình trạng ban hành văn bản pháp luật có sai trái về nội dung và thủ tục, hìn thức

Bên cạnh những văn bản quy phạm pháp luật được đầu tư xây dựng và có chất lượng tốt thì vẫn còn nhiều văn bản quy phạm pháp luật chưa phù hợp thực tiễn, khó thực hiện, thậm chí có những quy định pháp luật đang quá xa rời thực tế hay không muốn nói "trên trời". Tình trạng này gây nhiều khó khăn, phức tạp cho người dân và doanh nghiệp trong hoạt động sản xuất, kinh doanh. Các quy định đưa ra thiếu thực tiễn, bất hợp lý mà không có hội đồng thẩm định, phản biện một cách nghiêm túc. Tình trạng "giấy phép con" tuy đã được chỉ đạo quyết liệt để cắt giảm song hiện tại vẫn còn những quy định thủ tục hành chính bất cập, gây phiền hà cho người dân và doanh nghiệp.

Vẫn còn tình trạng nhiều văn bản pháp luật kém chất lượng, ở mức độ nhất định có còn trái pháp luật, vi phạm các quy định của văn bản Luật, gây ảnh hưởng tiêu cực đến quyền, lợi ích, đến ý thức và hành vi tôn trọng, tuân thủ pháp luật của người dân. Theo Báo cáo của Bộ Tư pháp về đánh giá hậu quả, tác hại của việc ban hành văn bản trái pháp luật gửi Thủ tướng Chính phủ, qua kiểm tra văn bản do các bộ ngành, địa phương ban hành, đã phát hiện 5.639 văn bản trái pháp luật. Trong đó, có tới 1.236 văn bản trái pháp luật về thẩm quyền ban hành và nội dung; hơn 3.829 văn bản sai sót về căn cứ pháp lý, thể thức kỹ thuật trình bày văn bản; 574 văn bản không phải là văn bản quy phạm pháp luật nhưng có chứa quy phạm pháp luật [10]. Chính phủ, sau khi xem xét báo cáo của Bộ Tư pháp về công tác kiểm tra, rà soát, hệ thống hóa văn bản quy phạm pháp luật năm 2017, Phó Thủ tướng Thường trực Trương Hòa Bình đã yêu cầu kiểm điểm, xử lý, đánh giá mức độ hoàn thành nhiệm vụ đối với người đứng đầu, tổ chức, cá nhân có liên quan trong việc ban hành văn bản trái pháp luật gây hậu quả nghiêm trọng [11].

2.6. Hạn chế về năng lưc, trình độ của đội ngũ cán bộ, công chức xây dựng pháp luật, chế độ trách nhiệm, chế tài xử lý vi phạm chưa được quy định đầy đủ, hơp lý

Xây dựng pháp luật là hoạt động rất phức tạp, chịu sự tác động bởi nhiều yếu tố khách quan và chủ quan. Thời gian qua, sở dĩ chúng ta đã đạt được nhiều kết quả, thành tựu quan trọng 
về xây dựng pháp luật là có sự đóng góp có chất lượng, hiệu quả của đội ngũ cán bộ, công chức tham gia xây dựng pháp luật. Tuy vậy, năng lực, trình độ, tầm nhìn của đội ngũ cán bộ, công chức về xây dựng pháp luật còn nhiều hạn chế và là một trong những nguyên nhân chủ yếu của tình trạng bất cập trong xây dựng pháp luật.

Việc đào tạo, bồi dưỡng chuyên sâu về xây dựng, phân tích chính sách, soạn thảo văn bản pháp luật chưa được thực hiện thường xuyên, bài bản, chế độ trách nhiệm cùng các chế tài xử lý vi phạm trong xây dựng pháp luật cũng mới chỉ dừng ở nguyên tắc chung là hai trong số nhiều nguyên nhân của những hạn chế về năng lực, trình độ và ý thức trách nhiệm của cán bộ, công chức làm công tác xây dựng pháp luật.

\section{Giải pháp chủ yếu nhằm khắc phục hạn chế, bất cập trong xây dựng pháp luật, đảm bảo chất lượng của văn bản quy phạm pháp luật}

Để khắc phục tình trạng hạn chế, bất cập của hệ thống pháp luật nói chung, hoạt động xây dựng pháp luật nói riêng, nâng cao chất lượng của các văn bản pháp luật cần phải thực hiện nhiều giải pháp đồng bộ vừa cấp bách, vừa lâu dài. Các nhóm giải pháp chủ yếu như: về cơ chế phân công, phối hợp, kiểm soát giữa các cơ quan có trách nhiệm xây dựng pháp luật, về đội ngũ cán bộ, công chức làm công tác xây dựng chính sách, pháp luật, về chế độ kiểm soát, trách nhiệm, xử lý vi phạm, về góp ý, phản biện xã hội, đánh giá tác động pháp luật. Dưới đây là một số giải pháp chủ yếu.

3.1. Xác định đầy đủ, rõ ràng, hợp lý hơn về chức năng, nhiệm vu của các co quan nhà nuớc, loại bỏ sư chồng chéo, đảm bảo thực hiện cơ chế phân công, phối hơp, kiểm soát quyền lực nhà nước trong xây dựng pháp luật

Đây là giải pháp rất căn bản để góp phần khắc phục những hạn chế, hoàn thiện hệ thống pháp luật, đảm bảo chất lượng các văn bản pháp luật. Mặc dù quy trình, thủ tục xây dựng pháp luật là điều kiện quan trọng, song nếu chỉ dừng lại ở quy trình, thủ tục thì vẫn chưa có thể khắc phục hoàn toàn được những hạn chế trong đó có sự chồng chéo, xung đột giữa các văn bản pháp luật như lâu nay. Hiện tại, cơ chế phân công, phôi hợp về xây dựng pháp luật của các cơ quan trong bộ máy nhà nước đang còn nhiều vấn đề bất hợp lý, chồng chéo chức năng, nhiệm vụ giữa các cơ quan có thẩm quyền xây dựng pháp luật.

Cách thức xây dựng - làm luật ở nước ta không do cơ quan chuyên trách, độc lập, đại biểu dân cử hoặc các ủy ban của Quốc hội chủ trì soạn thảo mà thường được giao cho cơ quan thuộc Chính phủ hoặc cơ quan trực tiếp quản lý nhà nước về ngành, lĩnh vực trực tiếp xây dựng. Một khi các cá nhân, cơ quan công quyền đã có thẩm quyền xây dựng pháp luật, có điều kiện, lại kèm theo "chế độ trách nhiệm phải hoàn thành nhiệm vụ xây dựng pháp luật theo tháng, quý, năm, nhiệm kỳ,... và theo cả chỉ tiêu thi đua,... nên rất dễ dàng" cài cắm lợi ích bộ, ngành, nhóm,...", và hiện tượng "đẽo cày giữa đường" khi làm luật, thực ra ở đây chủ yếu là liên quan đến lợi ích" [12].

Trách nhiệm của các cơ quan nhà nước có thẩm quyền là phải làm cho hệ thống pháp luật đơn giản, gọn nhẹ, khắc phục nhanh chóng sự phức tạp, rườm rà, số lượng quá lớn, khó tiếp cận, khó vận dụng và kiểm soát của hệ thống pháp luật hiện hành. Đây chính là một trong những điều kiện cơ bản đảm bảo cho tính hiện thực của các quyền, lợi ích của con người mà hiến pháp, pháp luật đã quy định.

Xây dựng, ban hành văn bản quy phạm pháp luật phải gắn với việc rà soát, đánh giá, xem xét, dự kiến bãi bỏ hoặc sửa đồi, bổ sung các quy định trong các văn bản quy phạm pháp luật có liên quan nhằm kịp thời loại bỏ những quy định lạc hậu, mâu thuẫn, chồng chéo, không đúng thẩm quyền, không minh bạch, bảo đảm tính thống nhất, đồng bộ, thực hiện nghiêm túc việc đánh giá tác động của chính sách, pháp luật.

3.2. Tăng cuờng kỷ luật, kỷ cuơng, quy định chế độ trách nhiệm, chế tài xủ lý vi phạm đối với cá cá nhân, tổ chức trong xây dựng pháp luật

Cần quy định chặt chẽ hơn về chế độ trách nhiệm cá nhân, trách nhiệm người đứng đầu, trách nhiệm giải trình về công tác xây dựng 
pháp luật. Quy định các chế tài pháp luật hợp lý, nghiêm khắc hơn đối với các chủ thể ban hành văn bản pháp luật sai trái, gây ảnh hưởng tiêu cực đến quyền, lợi ích của các cá nhân, tổ chức. Đối tượng để xem xét trách nhiệm bao gồm tập thể cơ quan có thẩm quyền ban hành văn bản; cá nhân người đứng đầu cơ quan; cán bộ, công chức trong quá trìn tham mư soạn thảo, thẩm định, thẩm tra, thông qua văn bản có nội dung trái pháp luật [13].

Kiểm soát để phát hiện, nhận diện vấn đề lợi ích nhóm trong các văn bản pháp luật. Không cài cắm vào luật những lợi ích nhóm làm ảnh hưởng đến lợi ích chung, lợi ích chính đáng của các cá nhân, tổ chức. Đây là thông điệp được đưa ra của Thủ tướng Nguyễn Xuân Phúc tại Hội nghị toàn quốc triển khai công tác tư pháp năm 2017 [14]. Theo kinh nghiệm của Hàn Quốc, cách tốt nhất để chống cài cắm chính sách là có một bộ phận chuyên môn độc lập làm việc này. Các dự thảo văn bản pháp luật phải được gửi cho đơn vị này để lấy ý kiến trước khi trình ký ban hành,..." [15].

Thủ tướng Chính phủ đã yêu cầu tăng cường kiểm tra, nâng cao kỷ luật, kỷ cương trong xây dựng, ban hành văn bản quy phạm pháp luật, xử lý kịp thời các sai phạm theo hướng: xem xét, xử lý trách nhiệm đối với người đứng đầu các cơ quan, đơn vị chủ trì soạn thảo; xác định rõ trách nhiệm của cơ quan, đơn vị, cá nhân trong việc tham mưu xây dựng, ban hành văn bản trái pháp luật; nâng cao trách nhiệm, chất lượng văn bản, phân công hợp lý hơn, phối hợp chặt chẽ hơn trong quá trình soạn thảo, thẩm định, thẩm tra, tiếp thu, chỉnh lý dự thảo luật, tránh tình trạng "giữa đường đổi vai"'[16].

\subsection{Thuc hiện nghiêm túc, có chất luơng viêc} lấy ý kiến góp ý, tham vấn, phản biện xã hội đối với chính sách, pháp luật

Để đảm bảo chất lượng, hiệu lực pháp lý và hiệu quả xã hội của các chính sách, văn bản pháp luật cần làm nghiêm túc công đoạn tổ chức lấy ý kiến, sự tham vấn của các chuyên gia, các tồ chức pháp lý, xã hội, người dân và doanh nghiệp. Trong Nghị quyết số 61/ NQ- CP về Phiên họp chuyên đề về xây dựng pháp luật tháng 8/2019 của Chính phủ đã xác định nhiệm vụ của các cơ quan chủ trì soạn thảo dự án, dự thảo văn bản quy phạm pháp luật phải chủ động lấy ý kiến của đối tượng chịu sự tác động; rà soát, kịp thời phát hiện các quy định pháp luật mâu thuẫn, chồng chéo, bất hợp lý, không phù hợp với tình hình thực tiễn và đề xuất hướng giải quyết [17].

Cần đổi mới cách tổ chức, xử lý, sử dụng thông tin của việc lấy ý kiến góp ý, phản biện chính sách và pháp luật đảm bảo khách quan, thực chất hơn. Cần thu hút sự tham gia ý kiến của các chuyên gia, doanh nghiệp và người dân ngay từ khâu xây dựng chính sách chứ không chỉ góp ý vào các Dự án, Dự thảo văn bản pháp luật. Các cơ quan, đơn vị tăng cường công tác tham vấn ý kiến các đối tượng chịu sự tác động của văn bản.

\subsection{Tăng cường năng lục và ý thức trách nhiệm của đội ngũ cán bộ, công chức tham gia xây dưng pháp luật, đảm bảo chất lương của dụ án, dụ thảo văn bản quy phạm pháp luật}

Xây dựng chính sách, pháp luật là công việc rất khó khăn, phức tạp, đòi hỏi những người trực tiếp thực hiện phải có trình độ chuyên môn sâu, có năng lực phân tích chính sách và soạn thảo văn bản pháp luật, có ý thức trách nhiệm tuân thủ các quy định pháp luật. Để đảm bảo tính chuyên nghiệp, cần xây dựng đội ngũ chuyên gia xây dựng chính sách, pháp luật được đào tạo, bồi dưỡng chuyên sâu về xây dựng chính sách và pháp luật.

Đề xuất đưa dự án luật vào Chương trình xây dựng pháp luật phải có đầy đủ căn cứ khoa học và thực tiễn; dự liệu được hết các yếu tố ảnh hưởng đến tiến độ và chất lượng thực hiện.

Để đảm bảo tính phù hợp, tính ổn định, tính chuẩn mực của văn bản pháp luật thì cần thực hiện tốt hai công đoạn chính trong quy trình xây dựng pháp luật là xây dựng chính sách và soạn thảo văn bản pháp luật.

Đồng thời, trong văn bản pháp luật cần được thể hiện rõ ràng những vấn đề cơ bản như: đối tượng có trách nhiệm thực hiện, cơ quan có trách nhiệm tổ chức thực hiện, cơ quan áp dụng 
chế tài; cơ quan giải quyết tranh chấp;cơ quan cấp vốn; cơ quan giám sát và đánh giá; cơ quan ban hành các văn bản dưới luật; cơ quan duy trì trật tự văn bản [19].

Trong văn bản quy phạm pháp luật cần thể hiện được sự cân bằng, hài hoà các loại lợi ích. Hài hòa, cân bằng các loại lợi ích là một trong những điều kiện căn bản để đảm bảo tính đúng đắn của các quy định pháp luật và tính khả thi của chúng trong thực tiễn. Hiệu lực và hiệu quả của pháp luật phụ thuộc vào sự tôn trọng cân bằng lợi ích của chủ thể thực thi pháp luật. Trên quan điểm đặt lên hàng đầu quyền, lợi ích của người dân trong xây dựng chính sách, pháp luật, Thủ tướng Chính phủ Nguyễn Xuân Phúc đã phát biểu trong phần trả lời chất vấn của các đại biểu Quốc hội vào ngày 1 tháng 11 năm 2018: "chúng ta phải hiểu và đặt sự lưu tâm đến từng người dân, không để bất kỳ ai bị bỏ sót hay cảm thấy bị bỏ sót trong các chính sách phát triển,... Luật pháp không cho phép chúng ta hợp thức hoá cái sai, không ai có quyền quyết định trái pháp luật" [20].

\section{Tài liệu tham khảo}

[1] Nguyễn Bá Chiến, Pháp luật triệt tiêu pháp luật, Tạp chí Nghiên cứu lập pháp số 74, tháng 4/2006.

[2] VCCI báo cáo nhanh về 20 điểm xung đột, chồng chéo lớn của pháp luật, https://bnews.vn/vcci-baocao-nhanh-ve-20-diem-xung-dot-chong-cheo-loncua-phap-luat-/130330.html.

[3] Nguyễn Thị Hồng Thắm, Sự chồng chéo về văn bản quy phạm pháp luật giữa thanh tra và kiểm toán, http://mt.gov.vn/vn/tin-tuc/61004/su-chongcheo-ve-van-ban-quy-pham-phap-luat-giua-thanhtra-va-kiem-toan.aspx.

[4] Cấp phép tràn lan, quản lý chồng chéo, http://vimico.vn/cap-phep-tran-lan-quan-lychong-cheo/.

[5] Xem, Phát biểu chỉ đạo của Thủ tướng Chính phủ Nguyễn Xuân Phúc trong Hội nghị toàn quốc triển khai công tác tư pháp năm 2017.

[6] Phan Phương, Đảm bảo tính ổn định và thống nhất của hệ thống pháp luật, http://baoxaydung.com.vn/dam-bao-tinh-on-dinhva-thong-nhat-cua-he-thong-phap-luat237294.html.

[7] Đinh Dũng Sỹ, Chính sách và mối quan hệ giữa chính sách với pháp luật trong hoạt động lập pháp,
Tạp chí Nghiên cứu Lập pháp số 127-thang-72008 ngày 20/07/2008.

[8] Phạm Chi Lan, Thể chế cho một chính phủ kiến tạo, http://www.doanhnhansaigon.vn/van-de/theche-cho-mot-chinh-phu-kien-tao/1102398/.

[9] Nguyễn Bình, Thay đổi tư duy, http://daibieunhandan.vn/default.aspx?tabid=76\& NewsId $=418229$.

[10] Bộ Tư pháp, "Ban hành văn bản trái pháp luật thể hiện sự "nhờn" luật", https://nld.com.vn/thoisu/bo-tu-phap-ban-hanh-van-ban-trai-phap-luatthe-hien-su-nhon-luat-20180808091902444.htm.

[11] Phó Thủ tướng chỉ đạo xử lý các văn bản trái luật,

[12] https://dantri.com.vn/xa-hoi/pho-thu-tuong-chidao-xu-ly-cac-van-ban-trai-luat20180815220104277.htm.

[13] Phạm Văn Chung, Để không làm luật kiểu "đẽo cày giữa đường".

[14] https://nld.com.vn/ban-doc/de-khong-lam-luatkieu-deo-cay-giua-duong20170115222730997.htm.

[15] Lê Thị Uyên, Xử lý trách nhiệm đối với người, cơ quan ban hành văn bản trái pháp luật, vi phạm trong hoạt động kiểm tra văn bản và việc khắc phục hậu quả, https://www.tapchitoaan.vn/baiviet/phap-luat/xu-ly-trach-nhiem-doi-voi-nguoico-quan-ban-hanh-van-ban-trai-phap-luat-vipham-trong-hoat-dong-kiem-tra-van-ban-va-vieckhac-phuc-hau-qua.

[16] Không cài cắm vào luật để phục vụ lợi ích riêng, http://vietnamnet.vn/vn/thoi-su/chinh-tri/thutuong-khong-cai-cam-vao-luat-noi-dung-khongvi-loi-ich-chung-348136.html\#inner-article.

[17] Nguyễn Minh Đức, Triệt tiêu tình trạng cài cắm chính sách trong xây dựng pháp luật, https://thanhnien.vn/chinh-tri/triet-tieu-tinh-trangcai-cam-chinh-sach-trong-xay-dung-phap-luat978708.html.

[18] Xây dựng thể chế pháp luật, phải theo sát đến cùng,

https://thongtinphapluat.bacgiang.gov.vn/web/gue st/chi-tiet-tin-tuc/-

/asset_publisher/St1DaeZNsp94/content/xay-

dung-the-che-phap-luat-phaitheosatdencung/pop_up?_101_INSTANCE_St1D aeZNsp94_viewMode=print\&_101_INSTANCE_ St1DaeZNsp94_languageId=vi_VN.

[19] Nghị quyết số 61 / NQ- CP về Phiên họp chuyên đề về xây dựng pháp luật tháng $8 / 2019$.

[20] Ann Seidman, Robert B. Seidman, Nalin Abeyesekers, Soạn thảo luật pháp vì tiến bộ xã hội dân chủ: Sổ tay cho nhà soạn thảo, Nxb. Chính trị Quốc gia, H. 2003, tr. 70 - 72. 